\title{
Adult Equivalence Scales: A Life-Cycle Perspective
}

\author{
JAMES BANKS, RICHARD BLUNDELL and IAN PRESTON*
}

\section{INTRODUCTION}

In any policy-orientated study of family welfare, it is inevitable that some comparison of welfare between households with different compositions will be required, and the theory of (adult) equivalence scales aims to formalise the way in which these comparisons may be made. An adult equivalence scale is defined as the proportionate increase in income per adult necessary to maintain a certain level of household living standard given some change in demographic circumstances (typically, the introduction of children). Values for such scales might be obtained in any of a number of ways. It is clear, for instance, that any national social security system can be interpreted as embodying one such set of scales; in the UK this is given by those reported in Table 1 . Scale 1 reports the adult equivalence scale implicit in the income support system, taking into account the 'family premium' a fixed amount paid to a household on income support with any number of children. So, for example, according to scale 1 , a child of age 10 or less is deemed to require 68.4 per cent of the expenditure of one adult. Scale 2 disregards the family premium and reports only the variable element of the implicit equivalence scale.

In this paper we are concerned with the advantages and limitations of economic analysis as an approach to the problem of equivalence scale measurement. In so far as economic analysis of family budgets can recover parameters representing household welfare, one might think that observing the effects of demographic change on expenditure decisions might help calculate such scales. In fact, as Pollak

\footnotetext{
* James Banks is a Research Officer at the Institute for Fiscal Studies; Richard Blundell is a Professor at University College London and Research Director of IFS; Ian Preston is a Research Fellow at Nuffield College, Oxford and a Research Associate at IFS.

This research was supported by funding from the ESRC and the Rowntree Foundation. The authors are grateful to Michael Devereux and an anonymous referee for providing helpful comments, and to the Department of Employment for providing data. All errors are their own.
} 
and Wales (1979) argue, this is somewhat misleading since analysis of budget data can at best identify only preferences over goods conditional on family structure and cannot identify crucial parameters determining preferences over family structure itself. None the less, economic methods based on some assumption regarding preferences over family composition have been very widely used.

TABLE 1

Income Support in the UK

\begin{tabular}{c|cc}
\hline Child's age & Scale I & Scale 2 \\
\hline $0-10$ & 0.684 & 0.429 \\
$11-15$ & 0.890 & 0.635 \\
$16-17$ & 1.015 & 0.760 \\
18 & 1.256 & 1.001 \\
\hline
\end{tabular}

Source: Calculated from Lakhani and Read (1990).

Historically, two methods have dominated the equivalence scale literature. The Engel (1895) method, still popular in many recent studies, makes the potentially attractive assumption that households of differing composition are at the same standard of living if the same proportion of their total expenditure is spent on food. The Rothbarth (1943) method (see Deaton, Ruiz-Castillo and Thomas (1989)), on the other hand, assumes a common standard of living is achieved by households consuming the same amount of some set of 'adult' goods (i.e. alcohol, adult clothing, etc.). Table 2 gives some idea of the wide range of scales that have been calculated by different, and even by the same, authors. These scales represent the cost of an additional child as a ratio of the cost of one adult, so that under the Muellbauer (1977) scale, for example, the ratio of minimum expenditures (or, equivalently, costs) required to attain a given level of utility of a household with two adults and one child to that of a household with two adults and no children would be 2.44/2.00. Moreover, recent work relating equivalence scales to cost of living indices has shown the dependence of the scales on relative prices, and therefore the sensitivity to the time at which the survey was conducted (see especially Blackorby and Donaldson (1991a) and Blundell and Lewbel (1990)).

All of these attempts to estimate equivalence scales from household responses to differences in demographic composition have concentrated attention upon differences in the composition of spending at one particular time. However, it is widely acknowledged that spending decisions are made with more than just one time period in mind. Recognition of this intertemporal context in which households make spending decisions forces one to consider the possible importance of responses involving cross-period transfers of spending, and that is the point of this paper. Indeed it might be thought that observing how the levels of spending change over time as a child arrives in a household should be a better way of measuring costs than simply focusing on within-period expenditure reallocations. 
TABLE 2

Some Equivalence Scales

\begin{tabular}{l|lcc}
\hline Source & Country & $\begin{array}{c}\text { Scale } \\
\text { (age=3) }\end{array}$ & $\begin{array}{c}\text { Scale } \\
\text { (age=12) }\end{array}$ \\
\hline Bojer (1977) & Norway & 0.47 & 0.47 \\
Muellbauer (1977) & UK & 0.28 & 0.44 \\
Muellbauer (1980) & UK & 0.17 & 0.52 \\
Lazear and Michael (1980) & USA & 0.42 & 0.42 \\
Van der Gaag and Smolensky (1982) & USA & -0.02 & 0.22 \\
Ray (1986) & UK & 0.12 & 0.12 \\
Deaton, Ruiz-Castillo and Thomas (1989) & Spain & 0.21 & 0.31 \\
Blundell and Lewbel (1990) & UK & 0.29 & 0.36 \\
\hline
\end{tabular}

Source: Expanded from Browning (1990).

If households are free to transfer spending between periods by borrowing or saving, ${ }^{1}$ it is not clear why one would want to assume that expenditure in other periods is unchanged when one evaluates relative standards of living. Given that the possibility of advantageous cross-period reallocation of expenditures is being ignored, the amount needed to restore within-period living standards keeping expenditures in other periods constant will overstate the amount needed to restore lifetime living standards allowing for reallocation, which one might think a more pertinent consideration. ${ }^{2}$ Households clearly can engage in this sort of intertemporal reallocation, perhaps delaying foreign holidays or restaurant meals until children have become more independent.

In this case we might think of compensating a household for the full lifetime costs of a child, allowing for intertemporal adjustment in the household's expenditure stream; we call the ratio of expenditures, measured over the entire lifetime, for two such households at common lifetime living standard a life-cycle equivalence scale. This might be contrasted with the usual equivalence scale defined as the ratio of expenditures within a given period of two households at a common within-period standard of living.

A further contrast might be between the standard equivalence scale and a life-cycle consistent equivalence scale - defined as the ratio between spending in a particular period for households at points along paths that are consistent with intertemporal reallocation of spending, and yield similar lifetime well-being. Either might serve as a useful tool for adjusting within-period incomes of different households onto a common basis for welfare comparison in, say, a study of poverty or income

I Perfect capital markets are assumed in much of what follows, but the statements made here are true provided any cross-period reallocation is possible.

2 This is not to say that our methodology need imply lower scales than others have found in studies ignoring intertemporal aspects, since there may be factors affecting within-period utility which cannot be picked up without intertemporal estimation. 
distribution. The former scale, though seemingly of limited interest other than in the study of households with no possibility of borrowing or saving in any period, will coincide with the latter only under very restrictive assumptions on household preferences.

Whatever purpose or interpretation we might attach to the scales, it makes little sense to think of scales simply depending on numbers of children in any particular period. The timing of children, the anticipation of their arrival and the anticipation of their future needs matter.

\section{EXPENDITURE PATTERNS OVER TIME}

Typically, to look at the kind of intertemporal issues that we have outlined above, one might prefer panel data to any other form of survey. Panel data observe a set of individuals repeatedly, and would allow us to trace the path of expenditures of individual households as the demographic composition of those households changes. Given the absence of such a data source in the UK at present, however, we take a series of cross-sectional surveys and draw on a large and growing literature to construct cohorts - groups of households in which the head of the household is born in the same five-year period. As each cohort is present in adjacent time periods of the sample (even though the individual members will have changed) we can construct a 'pseudo panel' by taking cohort averages. Rather than following a particular household through time, we are instead able to observe the behaviour of one particular cohort through time. We take UK Family Expenditure Survey data for the 20 years 1969-88 and select all households with two adults of less than 65 years of age - one male and one female - that are not resident in Northern Ireland. The remaining data set comprises 61,216 observations, which we pool to examine within-period behaviour, and from which we take cohort averages to analyse life-cycle issues. ${ }^{3}$

Having constructed such a data set we are able to look at unconditional paths of expenditure and demographics for each cohort across the periods of our sample in which they are present. In Figures $1 \mathrm{a}$ and $1 \mathrm{~b}$ each line (alternately solid and dashed) represents the path of one cohort (which is, by definition, at a different stage in the life cycle from the other cohorts at any particular time) through our sample. The first important characteristic of these cohort data is that total expenditure over the life cycle displays its familiar humped shape. Figure la shows total expenditure (excluding durables and housing) at January 1987 prices for the various segments of the life cycle in which each cohort is present. Remember that the sample extends over the period 1969-88 so that several cohorts can be tracked for as long as 20

\footnotetext{
3 With cohorts covering a five-year band this results in group sizes for each cohort that have been shown to be large enough to allow us to disregard sampling error and treat the data as a genuine panel (see, for example, Deaton (1985) or Verbeek and Nijman (1990)).
} 


\section{Fiscal Studies}

years. Not surprisingly, a simple plot of the number of children in the household describes a similar profile (as shown in Figure 1b) whilst displaying markedly less variation across either cohorts or the business cycle. Obviously this omits any children who have left home, but then these are no longer being covered by the expenditure in the household.

FIGURE 1a

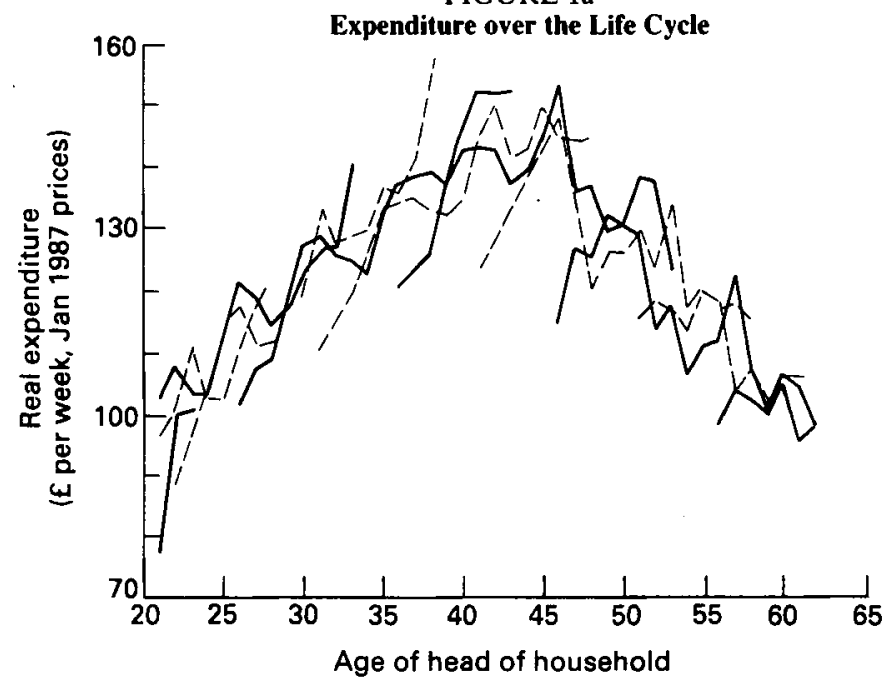

FIGURE $1 b$

Numbers of Children in the Household over the Life Cycle

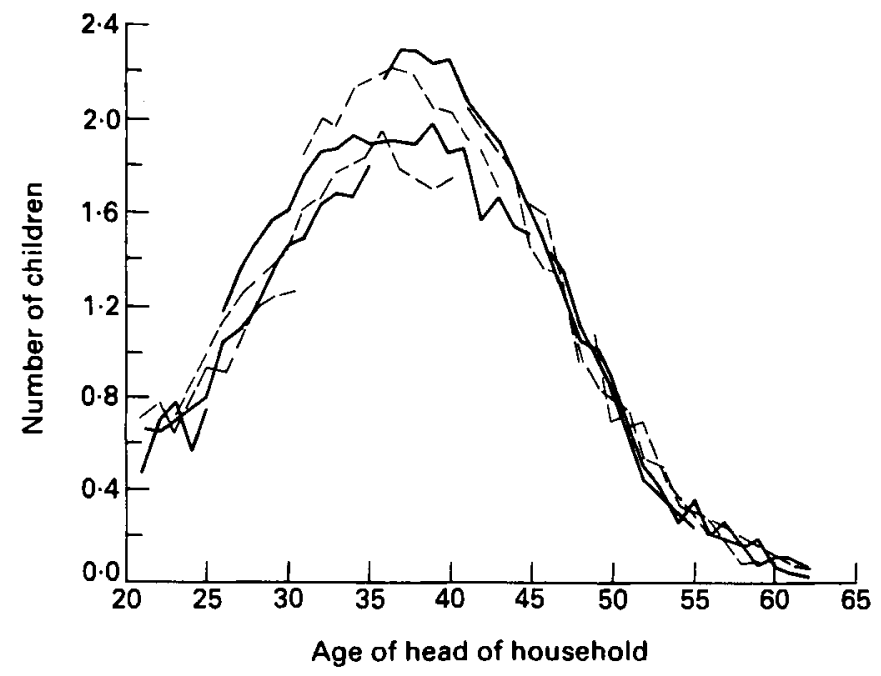


Figures $1 \mathrm{a}$ and $\mathrm{lb}$, then, might present some prima-facie case for examining the paths of expenditure and children together. However, the situation is not quite as straightforward as this. To investigate the pure costs of children we would like to be able to abstract both from business cycle and labour supply effects, and, more importantly for this paper, we would like to distinguish between those households that do not anticipate having children and those households that are intending to have children in the future. Since the anticipation of children tomorrow is likely to have expenditure implications today, not until we incorporate anticipated demographic paths can we build up an idea of how household behaviour changes in response to changes in household composition.

\section{EQUIVALENCE SCALES AND IDENTIFICATION ISSUES ${ }^{4}$}

In the first section of this paper we defined an equivalence scale as the ratio of minimum expenditures required to bring a comparison and a reference household to some common standard of living (or level of utility). When, as is often the case, we wish to compare households with different numbers of children, this could be alternatively thought of as embodying the amount of 'income' that we would need to give to a household with a certain number of children to compensate that household for the extra costs that are brought about by the presence of children.

A household can be thought of as having preferences jointly over consumption of goods and over its demographic composition. These preferences can be uniquely represented by a function that describes the minimum cost, at given prices, of attaining a given level of utility. This function can be used to derive a unique set of demands for goods, given the demographic composition of the household. There are problems, however, when one tries the reverse - recovering a utility function from the commodity demands. Observed consumption behaviour can only reveal information regarding preferences for marketed goods and cannot shed any light on preferences over the demographics themselves. (This is not to say that other behaviour, such as decisions relating to family size, or, for that matter, analysis of surveys asking respondents to form opinions on levels of welfare by introspection, could not in principle be useful in this area.)

The difficulty in identifying preferences over demographics has important implications for the equivalence scale literature, as was recognised by Pollak and Wales (1979). Estimation of an equivalence scale requires us to be able to recover preferences from observed demands for both reference and comparison households. We cannot do this without extraneous information identifying preferences over demographic attributes themselves. As Blundell and Lewbel (1990) establish, '... demand equations can be used to construct distinct cost of living indices for

4 For a formal derivation of the results used in both this and the next section, along with details of the theory behind our methodology and estimation techniques, the interested reader is referred to Banks, Blundell and Preston (1991). 


\section{Fiscal Studies}

households of any given composition, but demand equations alone provide no information about the relative cost of living of changing household composition in any selected reference price regime'. Indeed, since most households choose to have children, we might infer that there are unmeasured benefits to their presence which outweigh any lifetime costs and economic analysis simply fails to pick up - the pure joy of having children, one might say.

Although the economist may only be able to identify a subset of the parameters required for full welfare comparison, consideration of the intertemporal nature of household decision-making may both expand that subset and shed considerable light on the precise limitations of an economic model that tries to make such a comparison..$^{5}$ It is intuitively and analytically helpful to construct a sequential description of behaviour in approaching this problem. The process is essentially one of three stages: ${ }^{6}$

(i) intertemporal allocation decisions are made, conditional on demographics i.e. how much to spend in each period;

(ii) labour supply decisions are made, conditional on demographics and saving; ${ }^{7}$

(iii) within-period expenditure decisions are made, conditional on demographics, saving and labour market status - i.e. how to spend the period's income.

With this three-stage approach we can begin to build up some kind of 'picture' of household preferences. At each stage it is completely clear what information is required to analyse behaviour, and also which quantities are not subject to household choice in that stage. Consequently we can infer the welfare costs and benefits that are associated with changes in variables that are truly exogenous (i.e. predetermined) in all stages of the household decision-making process.

\section{DATA AND SIMULATION METHODOLOGY}

As already mentioned, we have data on 61,216 households from the UK Family Expenditure Survey for the period 1969-88. The size of this sample allows us to split the data into four demographic groups, for separate estimation of within-period preferences, according to the number of children in the household. Monthly price data are used on five commodities - food, fuel, clothing, alcohol, and other goods - to estimate a five-good demand system for non-housing, non-durable expenditure

\footnotetext{
5 As recognised in Pashardes (1991).

6 Again the Pollak and Wales (1979) point crops up, since the (logically preliminary) fertility decision is clearly beyond the scope of this demand-based economic analysis.

7 The analysis in later sections of this paper deals only with consumption costs and does not model loss of eamings explicitly. However, the methodology can easily be extended to incorporate this.
} 
shares. ${ }^{8}$ The functional form we take is an extension to the well-known Almost Ideal Demand System of Deaton and Muellbauer (1980), and our methodology follows closely that of Blundell, Pashardes and Weber (1989). ${ }^{9}$ Although our grouping does not represent a very fine level of disaggregation, it does allow us to address all the usual within-period questions associated with the equivalence scale literature.

To capture the intertemporal aspect of household decision-making, we make assumptions about intertemporal preferences which imply an associated Euler equation - a relationship between adjacent periods' expenditures which governs the evolution of optimal expenditure paths. ${ }^{10}$ At this stage two important parameters are introduced. The first determines the elasticity of intertemporal substitution, $\sigma$, a measure of how willing households are to reallocate their expenditures across time in response to changes in (anticipated) prices and interest rates, and therefore, by extension, to demographic composition. Clearly if this is large households will save a lot in anticipation of expensive periods when children are present, and consequently we might expect their utility paths to be smoother over time. In our model $\sigma$ is allowed to vary with the household's standard of living - poorer households being less willing to engage in life-cycle reallocations. The other important parameter is introduced to capture the desire of households to substitute expenditure away from relatively costly periods of child-rearing. We are presently pursuing research into behavioural estimation of these parameters from the consistently aggregated constructed cohort data described above, but for the purposes of this paper we are content to impose values and assess sensitivity of the derived paths.

With a set of parameters that can completely describe the path of expenditures over the life cycle, we can then simulate these paths for households with any chosen set of characteristics. We first choose a demographic path for both the reference and the comparison household. This includes characteristics such as region, employment status of both adults, cohort dummies, tenure, and whether there is a smoker in the household. Children are then allowed to enter the comparison household at some chosen point in the life cycle, and are assumed to remain there for 18 years, with the female adult being constrained to be out of the labour force while any child present is less than three years old. Given such a demographic structure we can allow the characteristics to evolve naturally (e.g. adults' ages to increase by one year in each period) and simulate the life cycle of any particular cohort. We can use the Euler

\footnotetext{
8 Modelling of housing and durable expenditure is complicated by issues of rationing, distinctions between stocks and flows, infrequency of purchase and so on, which we feel happier excluding from the present analysis.

9 That is to say, we estimate a share equation that is quadratic in the logarithm of real expenditure, using the Minimum Chi Square technique to impose symmetry restrictions across equations (see Ferguson (1958) and Rothenberg (1973)).

${ }_{10}$ To be precise, we assume additive separability over time, and perfect capital markets so that the marginal utility of discounted within-period expenditure remains constant (in expectation, if there is uncertainty) across periods (see Browning, Deaton and Irish (1985)). The details of intertemporal specification are close, in spirit, to Blundell, Browning and Meghir (1989).
} 


\section{Fiscal Studies}

equation to calculate consumption in the next period given current consumption and anticipated change in demographic composition, and can therefore apply this technique sequentially to construct the complete shape of lifetime consumption for each household given a choice of starting value. In addition, if we are prepared to make the appropriate identifying assumptions, ${ }^{11}$ we can evaluate lifetime 'utility' and construct the paths such that this is equal between reference and comparison cases. A life-cycle equivalence scale would be the ratio of lifetime expenditures associated with two such paths, and a life-cycle consistent equivalence scale would be the ratio of within-period expenditures on two such paths at some time $t$. However, given our discussion of identification in Section III, we would prefer to stress the simulated paths of expenditures (which are completely identified) as opposed to the utilities associated with the expenditures (which are not) as the important result of this study.

\section{RESULTS}

In Table 3 we report a within-period equivalence scale based solely upon our within-period data and drawn from Blundell and Lewbel (1990). In contrast to many scales reported in the literature, we have allowed the age of the child to have a varying impact on the household's cost function. Remember that these scales do not cover expenditure on housing and durable goods, a significant proportion of total consumption.

TABLE 3

A Within-Period Equivalence Scale

\begin{tabular}{cc}
\hline Child's age & Scale \\
\hline $0-2$ & 0.182 \\
$3-5$ & 0.287 \\
$6-10$ & 0.328 \\
$11-18$ & 0.361 \\
\hline
\end{tabular}

Our model for within-period demands and intertemporal substitution allows us to construct life-cycle expenditure paths for households with different demographic composition and with different overall levels of life-cycle wealth. To do this we follow the simulation methodology of Section IV and assess the sensitivity of our results, in particular to the degree of intertemporal substitution. ${ }^{12}$ Although we do

"Through choice of functional form representing preferences over children (see Banks, Blundell and Preston (1991)).

${ }_{12}$ Simplifying by assuming that the real interest rate is equal to the household's subjective discount rate in all periods. 
not explicitly assess the sensitivity to the choice of initial period consumption for the reference path, we recognise that this has implications for the calculation of scales. ${ }^{13}$

These issues are effectively illustrated in Figures 2 and 3 where comparisons of life-cycle expenditure profiles are presented.

Figure 2 shows 'life-cycle-expenditure-constant' paths for four different demographic profiles with an elasticity of intertemporal substitution (at base consumption for the reference household) of -0.74 . The reference household has no children at any point, but its expenditure path slopes slightly upward due to age effects. The demographics of Path 1 are identical in every way except that a child is born when the head of household is 26 years of age. Path 2 has two children born when the head is 26 and 28 - and Path 3 has three children, born at the ages of 26,28 and 30 . We see that households with more children have to bear higher costs in some periods, and therefore (since total lifetime expenditure is constant) spend less in the periods before and after the children. Remember that we are considering anticipated changes only, so that households expecting higher costs in the future due to the presence of children will try to save in anticipation of that event.

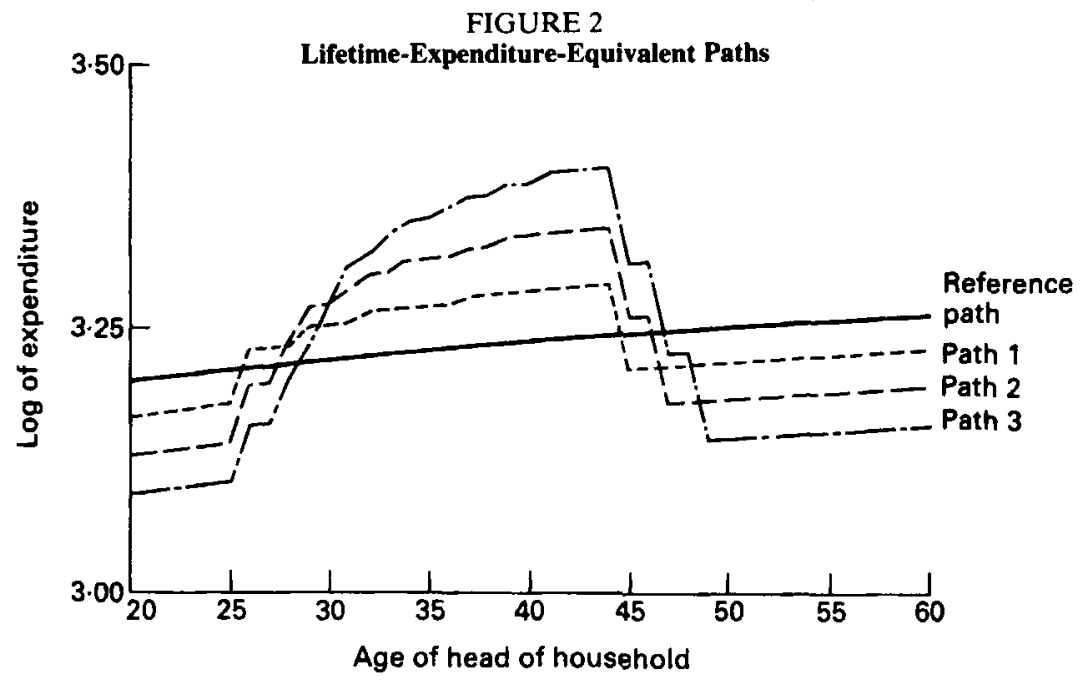

If we choose to specify a form for lifetime utility embodying an implicit (and essentially arbitrary) identifying assumption regarding preferences over children, we could construct paths such that lifetime utility rather than lifetime expenditure is constant. In this situation we could also calculate the life-cycle and life-cycle consistent equivalence scales associated with such paths. Figures $3 a, 3 b$ and $3 c$

${ }^{13}$ The scales are not independent of the utility level on the reference path. In the terminology of Lewbel (1990), they are not 'independent of base' (IB); equivalently, in that of Blackorby and Donaldson (1991a and 1991b), our life-cycle utilities do not satisfy 'Equivalence Scale Exactness'. 


\section{Fiscal Studies}

FIGURE 3

Expenditure Paths and Intertemporal Substitution

$\mathrm{a}: \sigma=-1.00$
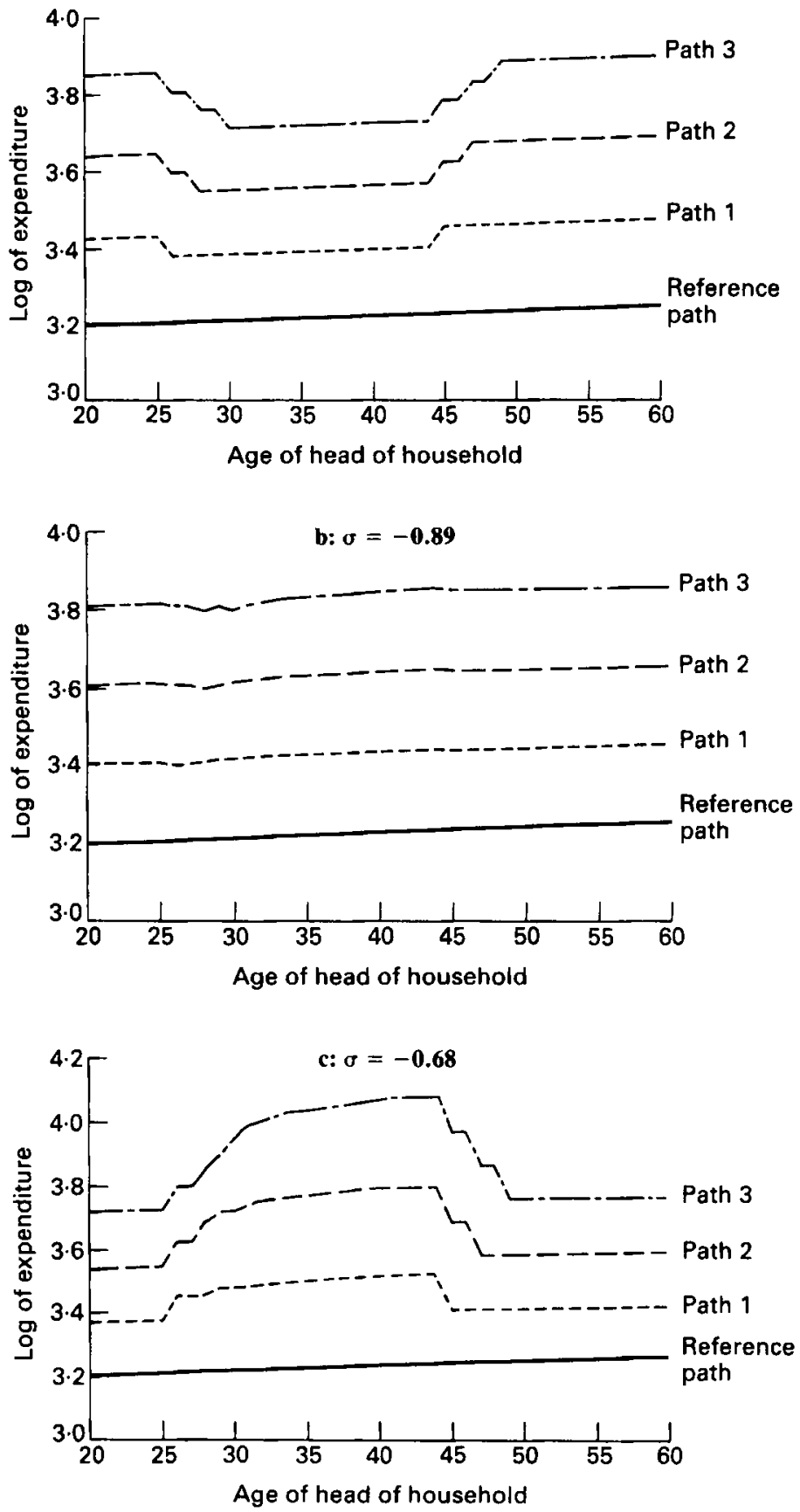
present comparisons of life-cycle dynamic paths on this basis as the elasticity of substitution varies. Households are now encouraged to substitute expenditure away from periods with children if the elasticity of substitution is large enough, and this could, in theory, be sufficiently extreme to mean that expenditure paths may actually dip as children enter the household. For a given path of demographics the expenditure path is dipped when the substitution elasticity is -1 (Figure 3a), flattens (Figure $3 b$ ) and then arches upward (Figure $3 c$ ) as willingness to substitute between periods decreases.

Likewise, as $\sigma$ falls it can be seen that the required lifetime compensation increases as outlined in the lifetime equivalence scale in Table 4 . The within-period scales (which compare points at the same time on different paths) are more sensitive to changes in the shape of the path, and the point in the life cycle at which the comparison is made, than the lifetime scales (which, loosely speaking, compare areas beneath them).

TABLE 4

Life-Cycle Equivalence Scales

\begin{tabular}{|c|c|c|}
\hline Demographic profile & $\begin{array}{l}\text { Life-cycle } \\
\text { equivalence } \\
\text { scale }\end{array}$ & $\begin{array}{c}\text { Life-cycle } \\
\text { consistent } \\
\text { equivalence scale } \\
\text { (age 40) }\end{array}$ \\
\hline \multicolumn{3}{|l|}{$\sigma=-1.00$} \\
\hline $\begin{array}{l}\text { Path 1: One child when } \mathrm{HoH} \text { is aged } 26 \\
\text { Path 2: Children when } \mathrm{HoH} \text { is aged } 26 \text { and } 28 \\
\text { Path 3: Children when } \mathrm{HoH} \text { is aged } 26,28 \text { and } 30 \\
\sigma=-0.89 \text { (base period, reference household) }\end{array}$ & $\begin{array}{l}0.222 \\
0.482 \\
0.791\end{array}$ & $\begin{array}{l}0.189 \\
0.403 \\
0.649\end{array}$ \\
\hline $\begin{array}{l}\text { Path 1: One child when } \mathrm{HoH} \text { is aged } 26 \\
\text { Path 2: Children when } \mathrm{HoH} \text { is aged } 26 \text { and } 28 \\
\text { Path 3: Children when } \mathrm{HoH} \text { is aged } 26,28 \text { and } 30 \\
\sigma=-0.68 \text { (base period, reference household) }\end{array}$ & $\begin{array}{l}0.226 \\
0.500 \\
0.836\end{array}$ & $\begin{array}{l}0.232 \\
0.514 \\
0.856\end{array}$ \\
\hline $\begin{array}{l}\text { Path 1: One child when } \mathrm{HoH} \text { is aged } 26 \\
\text { Path 2: Children when } \mathrm{HoH} \text { is aged } 26 \text { and } 28 \\
\text { Path 3: Children when } \mathrm{HoH} \text { is aged } 26,28 \text { and } 30\end{array}$ & $\begin{array}{l}0.234 \\
0.535 \\
0.926\end{array}$ & $\begin{array}{l}0.315 \\
0.738 \\
1.293\end{array}$ \\
\hline
\end{tabular}

\section{CONCLUSIONS}

Our purpose in this paper has not been to estimate a set of equivalence scales - we have asserted that full comparisons of inter-personal welfare are not possible from demand data alone. This point applies equally to all standard equivalence scales based on expenditure survey data. What we have shown, however, is the importance of a life-cycle setting that recognises the dependence of expenditure patterns on the lifetime demographic profile of the household. This pattern is extremely sensitive 


\section{Fiscal Studies}

to assumptions about intertemporal parameters.

Any form of equivalence scale that recognised the intertemporal aspects of household decision-making would depend on the shape of the lifetime expenditure profiles. We believe that these intertemporal processes are important, and therefore for policy purposes (given the need for some monetary level of compensation) we need to look outside simple current-period models and acknowledge the intertemporal factors that influence the household decision-making process.

The main reason households do not substitute expenditures over time may well be not that they are unwilling, but that they are unable. In particular this may be true at the lower end of the income distribution, where willingness to substitute may be lower anyway, and may reduce the importance of these considerations for poorer households. Arguably the most important application of the equivalence scale literature relates to the compensation of households in poverty which one might therefore think should be greater than that which the methodology of this paper would suggest. In addition, any such 'failure' in the market for credit (e.g. households being unable to borrow against their human capital) could be one justification for the existence of period-specific compensation such as child benefit.

Finally we would say that, at present, all UK studies have to make use of static cross-sectional data and this makes consideration of dynamic issues difficult. Although construction of pseudo-panel data has been shown to be useful, it would be interesting to address these issues with a genuine panel study. The advent of the British Household Panel Survey could well go some way towards meeting this need, although there is some doubt as to the adequacy of the prospective consumption information.

\section{REFERENCES}

Banks, J. W., Blundell, R. W. and Preston, I. P. (1991), 'Equivalence scales and the life-cycle costs of children', Institute for Fiscal Studies Working Paper, forthcoming.

Blackorby, C. and Donaldson, D. (1991a), 'Adult-equivalence scales, interpersonal comparisons of well-being, and applied welfare economics', in J. Elster and J. Roemer (eds), Interpersonal Comparisons and Distributive Justice, Cambridge: Cambridge University Press.

- and - (199lb), 'Equivalence scales and the cost of children', University of British Columbia Discussion Paper.

Blundell, R. W., Browning, M. J. and Meghir, C. (1989), 'A microeconometric model of intertemporal substitution and consumer demand', Institute for Fiscal Studies, Micro to Macro Paper no. 4.

- and Lewbel, A. (1990), 'The information content of equivalence scales', Journal of Econometrics, forthcoming.

-, Pashardes, P. and Weber, G. (1989), 'What do we learn about consumer demand patterns from micro-data?', Institute for Fiscal Studies, Micro to Macro Paper no. 3.

Bojer, H. (1977), 'Effect on consumption of household size and composition', European Economic Review, vol. 9, pp. 169-93.

Browning, M. J. (1990), 'Modelling the effects of children on household economic behaviour', McMaster University Working Paper no. 90-11. 
-, Deaton, A. S. and Irish, M. J. (1985), 'A profitable approach to labour supply and commodity demands over the life-cycle', Econometrica, vol. 53, pp. 503-43.

Deaton, A. S. (1985), 'Panel data from time series of cross sections', Journal of Econometrics, vol. 30 , pp. 109-26.

- and Muellbauer, J. N. J. (1980), 'An Almost Ideal Demand System', American Economic Review, vol. 70, pp. 312-26.

-, Ruiz-Castillo, J. and Thomas, D. (1989), 'The influence of household composition on household expenditure patterns: theory and Spanish evidence', Journal of Political Economy, vol. 97, no. 1, pp. 179-200.

Engel, E. (1895), 'Die Lebenskosten Belgischer Arbeiter-Familien früher and jetzt', International Statistical Institute Bulletin, vol. 9, pp. 1-74.

Ferguson, T. (1958), 'A method of generating best asymptotically normal estimates with application to the estimation of bacterial densities', Annals of Mathematical Statistics, vol. 29, pp. 1046-61.

Lakhani, B. and Read, J. (1990), National Welfare Benefits Handbook, 20th edition, London: Child Poverty Action Group.

Lazear, E. and Michael, R. (1980), 'Family size and the distribution of real per capita income', American Economic Review, vol. 70, no. 1, pp. 91-107.

Lewbel, A. (1990), 'Household equivalence scales and welfare comparisons', Journal of Public Economics, vol. 39, pp. 377-91.

Muellbauer, J. N. J. (1977), 'Testing the Barten model of household composition effects and the costs of children', Economic Journal, vol. 87, pp. 460-87.

- (1980), 'The estimation of the Prais-Houthakker model of equivalence scales', Econometrica, vol. 48 , no. 1, pp. 153-76.

Pashardes, P. (1991), 'Contemporaneous and intertemporal child costs: equivalent expenditures vs. equivalent income scales', Journal of Public Economics, forthcoming.

Pollak, R. A. and Wales, T. J. (1979), 'Welfare comparisons and equivalence scales', American Economic Review, vol. 69, pp. 216-21.

Ray, R. (1986), 'Demographic variables and equivalence scales in a flexible demand system: the case of AIDS', Applied Economics, vol. 18, pp. 265-78.

Rothbarth, E. (1943), 'Note on a method of determining equivalent income for families of different composition', Appendix 4 in C. Madge, War-Time Pattern of Saving and Spending, Occasional Paper no. 4, Cambridge: Cambridge University Press.

Rothenberg, T. J. (1973), Efficient Estimation with a priori Information, Cowles Foundation Monograph no. 23, Yale: Yale University Press.

Van der Gaag, J. and Smolensky, E. (1982), 'True household equivalence scales and characteristics of the poor in the United States', Review of Income and Wealth, vol. 28, no. 1, pp. 17-28.

Verbeek, M. and Nijman, T. (1990), 'Can cohort data be treated as genuine panel data?', mimeo, Tilburg University. 